\title{
HACIA UN NUEVO MODELO DE TRATADO BILATERAL DE INVERSIONES PARA MÉXICO*
}

\author{
TOWARDS A NEW MODEL OF BILATERAL INVESTMENT TREATY \\ FOR MEXICO
}

\section{Virdzhiniya Petrova GeOrgIEva**}

RESUMEN: El régimen jurídico de los tratados bilaterales de inversiones (en adelante TBI) se encuentra inmerso en una profunda crisis estructural. En este contexto, muchos países re-negocian o denuncian sus TBI vigentes. Otros han ido más lejos y ya han adoptado nuevos modelos de TBI. México parece quedarse al margen de esta crisis global de la regulación jurídica internacional de las inversiones extranjeras. Adicionalmente, algunas decisiones gubernamentales recientes convierten a México en un país, de facto, promotor de la permanencia del actual diseño jurídico-institucional de los TBI. No obstante, en la actualidad, resulta urgente modificar la política exterior de México en la materia y, con este fin, adoptar un nuevo modelo de TBI para nuestro país.

Palabras clave: tratados bilaterales de inversiones, arbitraje internacional, crisis, reformas.
ABSTRACT: The legal regime of bilateral investment treaties (BIT) is suffering a deep structural crisis. In this context, many countries have decided to renegotiate or to denounce their BITS. Others have gone further and have adopted already new BIT models. Mexico is not taking part in the debates surrounding this global crisis of the investment protection regime in international law. Additionally, some recent governmental decisions are transforming Mexico in a, de facto, promoter of the consolidation of the current legal and institutional design of BITs. However, it is urgent to modify Mexico's foreign policy in this area and, in this sense, to adopt a new BIT model for our country.

Key zords: bilateral investment treaties, international arbitration, crisis, reforms.

* Recibido el 3 de diceimbre de 2019; aprobado el 20 de octubre de 2020.

* ORCID: 0000-0002-4468-5940. Profesora-investigadora Universidad Nacional Autónoma de México: investigadora en el Instituto de Investigaciones Jurídicas y profesora en la Facultad de Derecho. Correo electrónico: virginia.geor@ gmail.com.

Boletín Mexicano de Derecho Comparado, nueva serie, año LIII, núm. 158, mayo-agosto de 2020, pp. 863-894. 
SUMARIO: I. Introducción. II. Las causas de la crisis del actual régimen jurídico internacional de los TBI. III. La adopción de nuevos modelos de TBI por algunos Estados miembros de la comunidad internacional. IV. La adopción de un nuevo modelo de TBI para México. V. Conclusión. VI. Referencias.

\section{INTRODUCGIÓN}

A partir de los años ochenta los Estados miembros de la comunidad internacional se abrieron a los flujos de las inversiones extranjeras directas (en adelante IED) porque consideraron que dichas operaciones aportarían el capital necesario para estimular su desarrollo económico; además, al transferir tecnología a las empresas nacionales, las IED crearían empleos y lograrían un efecto de desbordamiento del conocimiento, particularmente benéfico para la competitividad de sus sectores industriales internos. Para obtener estos beneficios, los países desarrollados acordaron con los países en vía de desarrollo la constitución de un régimen jurídico internacional protector de las IED.

A este efecto, a partir de los años noventa, se celebraron tratados internacionales de inversiones que se subdividen en: tratados bilaterales de inversiones — más de 3200, en la actualidad - y acuerdos de liberalización comercial que contienen disposiciones, relativas a las IED - más de 270, en la actualidad-. El resultado directo de este fenómeno consistió en la creación de una entramada red de acuerdos, en la que todos los países del mundo son parte de, al menos, un tratado internacional de inversiones (Organización de Naciones Unidas 2009, 1, en adelante ONU). El objetivo principal de todos estos convenios y, en particular, de los TBI, consiste en promover las IED, al otorgar a los inversionistas extranjeros una protección jurídica eficaz frente a determinados riesgos políticos en el país "huésped". ${ }^{1}$ Asimismo, las disposiciones de los TBI buscan garantizar la seguridad, previsibilidad y estabilidad jurídica en el trato que recibe

1 El riesgo político que enfrentan los inversionistas extranjeros en el país huésped se relaciona, en particular, con la soberanía del Estado. El Estado - sujeto soberano tanto de derecho interno como de derecho internacional - es competente para adoptar sobre su territorio cualquier tipo de actos, de naturaleza legislativa, administrativa, judicial, etcétera. En el ejercicio de dichas capacidades soberanas, el Estado puede ser llevado a vulnerar los derechos individuales de un inversionista extranjero, especialmente sus derechos de propiedad.

Esta obra está bajo una Licencia Creative Commons

Atribución-NoComercial-SinDerivar 4.0 Internacional, IIJ-UNAM.

Boletín Mexicano de Derecho Comparado, núm. 158, mayo-agosto de 2020, pp. 863-894. 
el inversionista, mientras desarrolla su actividad económica en el territorio de dicho Estado. La desconfianza inicial de los inversionistas hacia la eficacia de las reglas de protección de las IED, previstas en el derecho interno de los países condujo a la "objetivación" de dicha protección, por medio de su inclusión en normas de derecho internacional, negociadas de común acuerdo.

La protección jurídica que otorgan los TBI a los inversionistas extranjeros se basa, en primer lugar, en el establecimiento de determinadas reglas de "trato favorable" para estos operadores económicos. Dichas reglas se materializan en disposiciones sustanciales del tratado que garantizan, entre otros, el estándar de "trato nacional", y "trato justo y equitativo", 3 la debida indemnización en caso de expropiación, ${ }^{4}$ la libre transferencia del capital y de los beneficios de las IED $^{5}$ y la regulación de las exigencias de contenido nacional. ${ }^{6}$ En segundo lugar, dichos acuerdos buscan garantizar el cumplimiento de las reglas antes mencionadas por del recurso al

2 Así por ejemplo, en virtud del artículo 1102 del Tratado del Libre Comercio de América del Norte (en adelante TLCAN): "Cada una de las Partes otorgará a los inversionistas de otra Parte un trato no menos favorable que el que otorgue, en circunstancias similares, a sus propios inversionistas en lo referente al establecimiento, adquisición, expansión, administración, conducción, operación, venta u otra disposición de las inversiones (...)".

3 A título de ejemplo, el artículo 1105 del TLCAN establece que: "Cada una de las Partes otorgará a las inversiones de los inversionistas de otra Parte, trato acorde con el derecho internacional, incluido trato justo y equitativo, así como protección y seguridad plenas".

4 Según lo dispuesto en el artículo 1110 del TLCAN: "Ninguna de las Partes podrá nacionalizar ni expropiar, directa o indirectamente, una inversión de un inversionista de otra Parte en su territorio, ni adoptar ninguna medida equivalente a la expropiación o nacionalización de esa inversión (expropiación), salvo que sea: (...) (d) mediante indemnización (...)".

5 En virtud del artículo 1109 del TLCAN: "Cada una de las Partes permitirá que todas las transferencias relacionadas con la inversión de un inversionista de otra de las Partes en territorio de la Parte, se hagan libremente y sin demora (...)".

6 Por ejemplo, conforme con el artículo 1106 del TLCAN: "Ninguna de las Partes podrá imponer ni hacer cumplir cualquiera de los siguientes requisitos o hacer cumplir ningún compromiso o iniciativa, en relación con el establecimiento, adquisición, expansión, administración, conducción u operación de una inversión de un inversionista de una Parte o de un país no Parte en su territorio para" (...) (b) alcanzar un determinado grado o porcentaje de contenido nacional; (c) adquirir o utilizar u otorgar preferencia a bienes producidos o a servicios prestados en su territorio, o adquirir bienes de productores o servicios de prestadores de servicios en su territorio (...)". 
arbitraje internacional para el arreglo de los litigios que surjan de la interpretación o aplicación de sus disposiciones. ${ }^{7}$ El recurso a órganos arbitrales, imparciales e independientes de las partes en la controversia, es visto como un componente esencial del carácter protector de los TBI porque "eleva" el conflicto entre el inversionista extranjero y el Estado "huésped" en el plano internacional, evitando así los riesgos asociados con su resolución por los tribunales internos de dicho país (David y Michael 2015, 3). ${ }^{8}$

Así concebido, el régimen jurídico internacional protector de las IED se desarrolló durante las últimas décadas del siglo XX y los TBI siguieron multiplicándose considerablemente. No obstante, en la actualidad, dichos tratados son objeto de cada vez más vivas crítica tanto respecto a la aplicación de sus disposiciones sustanciales, como en lo relativo a su mecanismo arbitral de solución de controversias. Consecuentemente, muchos países están re-examinando sus políticas de regulación de las IED. Algunos de estos países re-negocian o anuncian la re-negociación de sus TBI vigentes. Otros han ido más lejos y se han retirado o han expresado su decisión de denunciar sus TBI u otros tratados que establecen el arbitraje internacional como mecanismo de arreglo de diferencias en materia de inversiones. Finalmente, varios Estados han adoptado nuevos modelos de TBI. Así por ejemplo, en mayo de 2017, la Asamblea Nacional de Ecuador aprobó la denuncia de 12 TBI suscritos con: China, Chile, Venezuela, Países Bajos, Suiza, Canadá, Argentina, Estados Unidos, España, Perú, Bolivia e Italia (Mena, 2010). Tres países latinoamericanos denunciaron el Convenio de Washington de 1965 que creó al Centro Internacional de Arreglo de Diferencias sobre Inversiones (en adelante CIADI), primero Bolivia en 2008 (Valverde 2008), después Ecuador en 2009 (Boeglin 2013) y, finalmente, Venezuela en 2012 (Ripinsky 2012). Desde 2014, Bolivia anunció, además, su intención de denunciar sus TBI. De igual modo, a partir de

7 Así, por ejemplo, el artículo X del TBI, celebrado entre México y España establece que: "Si la controversia no pudiera resolverse de ese modo en un plazo de seis meses desde el inicio de las negociaciones, será sometida, a petición de cualquiera de las dos Partes Contratantes, a un tribunal de arbitraje".

8 El principal obstáculo para el sometimiento de controversias entre Estados e inversionistas extranjeros a tribunales internos tiene que ver con la imparcialidad e independencia de dichos órganos judiciales. Como lo señala Sloss, en aproximadamente dos terceras partes de los países del mundo, el Poder Judicial no es independiente. En dichos países, los intereses políticos de las personas en el poder subvierten el derecho y el derecho internacional, de manera casi rutinaria (Sloss y Van Alstine 2015). 
2014, Sudáfrica, Indonesia The Centre for Research on Multinational Corporations (2014, en adelante SOMO) o India (Nicholas, Donny y Kritika 2016), decidieron re-negociar o terminar sus TBI. A partir de 2017, India, Países Bajos o la República Checa, entre otros, adoptaron nuevos modelos de TBI.

México parece quedarse al margen de esta crisis global del régimen jurídico actual de los TBI y del arbitraje internacional de inversiones.

En efecto, México cuenta con 33 TBI o Acuerdos para la Promoción y la Protección Recíproca de Inversiones (APPRI ${ }^{9}$ con países de todas las regiones geográficas del mundo; ${ }^{10} 21$ de estos acuerdos ya concluyeron con su fase inicial de aplicación, prevista por 10 años; consecuentemente, México podría renegociar sus disposiciones o denunciarlos antes de 2020. No obstante, el gobierno mexicano no sólo no ha anunciado su intención de renegociar o retirarse de los APPRI vigentes, sino que ha celebrado un importante número de nuevos acuerdos en materia de inversiones: un TBI en 2013 con Kuwait; otro, en 2015, con Brasil y Haití, y el último, en 2016, con los Emiratos Árabes Unidos. Adicionalmente, México ha celebrado 11 TLG que cuentan con un capítulo sobre inversiones, cuyas disposiciones sustanciales y mecanismo de solución de controversias, están directamente inspirados del actual régimen de los TBI. ${ }^{11}$ De igual modo, México no sólo no ha anunciado su intención de revisar el contenido de los capítulos sobre inversiones, contenidos en dichos acuerdos, sino que también ha negociado recientemente dos nuevos TLC, con un régimen de protección jurídica de las IED casi idéntico al de los acuerdos anteriores. ${ }^{12}$

9 En adelante dichos términos se utilizarán como sinónimos.

10 Entre otros, con: Alemania, Argentina, Australia, Bahrein, Belarus, China, Corea, Cuba, Dinamarca, Emiratos Arabes Unidos, Eslovaquia, España, Finlandia, Francia, Grecia, Haití, India, Islandia, Italia, Kuwait, Países Bajos, Panamá, Portugal, Reino Unido, República Checa, Singapur, Suecia, Suiza, Trinidad y Tobagó y Turquía.

11 En particular: el Acuerdo Integral y Progresivo para la Asociación Transpacífica de 2018; el Protocolo Adicional de la Alianza del Pacífico de 2016; el TLC con Panamá de 2015; el TLG con Perú de 2012; el TLG con el Mercado Común Centroamericano de 2013; el TLG con Uruguay de 2004; el Acuerdo Económico con Japón de 2005; el TLC con Chile de 1999; el TLC con Nicaragua de 1998; el TLC con Colombia y Venezuela de 1996, y el TLCAN de 1994. https://aplicaciones.sre.gob.mx/tratados/consulta_nva.php.

12 Así, en 2018, México fue el primer Estado en ratificar el Acuerdo Integral y Progresivo para la Asociación Transpacífica y también el primero de los 3 países de América del 
La ausencia de iniciativas para modificar el actual régimen de tratados, celebrados por México en materia de inversiones, contrasta drásticamente con el número de demandas iniciadas en contra de nuestro país ante órganos arbitrales internacionales sobre la base de la aplicación de dichos acuerdos. México es el tercer país más demandado de la región de América Latina y el Caribe y el 5 país más demandado del mundo, con 31 casos, en total, de demandas presentadas en su contra por parte de inversionistas extranjeros ante tribunales arbitrales internacionales Transnational Institute (2020, en adelante TNI). En 53\% de estos casos ganaron los inversionistas extranjeros y perdió el Estado mexicano. El monto total que se acordó a los inversionistas como indemnización por las constatadas violaciones de distintos tratados de inversiones equivale a 243 millones de dólares, que fueron cubiertos por el erario público (TNI 2020). Este monto no incluye los costos de los arbitrajes, en sí, que, exceden, en promedio, los 5 millones de dólares, por cada caso. A pesar de estos antecedentes contenciosos, México se ha mostrado fiel al fortalecimiento de las instituciones internacionales que los promueven. Prueba irrefutable de ello es la decisión reciente del Estado mexicano de ratificar la Convención de Washington de 1965 y de convertirse, a partir de 2018, en un miembro de pleno derecho del CIADI.

Estas decisiones gubernamentales convierten a México en un país, de facto, promotor de la permanencia del actual régimen jurídico internacional de los TBI y lo ubican en una postura de oposición al creciente número de Estados miembros de la comunidad internacional que demandan la urgente reforma del mismo.

Resulta apremiante repensar esta posición del gobierno mexicano. México atraviesa en estos momentos por una coyuntura de cambios internos que deben ir acompasados con ajustes en su política exterior. Dentro de un innegable contexto de globalización, los cambios internacionales afectan a nuestro país y, al mismo tiempo, México puede ser partícipe de transformaciones externas necesarias para hacer frente a la crisis del régimen jurídico internacional protector de las IED. En vista de lo anterior, la hipótesis principal del presente trabajo consistirá en sostener que es necesario modificar la política exterior de México en materia de protección de las IED y, con este fin, adoptar un nuevo modelo de TBI para nuestro país.

Norte en aprobar el nuevo T-MEG que reintegra, en lo esencial, y para la relación entre México y Estados Unidos, las disposiciones del viejo TLCAN en materia de inversiones. 
La primera parte de la investigación se centrará en analizar las causas de la crisis del actual régimen jurídico de los TBI (II), y las críticas que formulan al respecto tanto países desarrollados como países en vía de desarrollo. En la segunda parte, se estudiarán las iniciativas de reforma a dicho régimen y se discutirán las modificaciones incluidas en los nuevos modelos de TBI, adoptados en la materia por algunos Estados miembros de la comunidad internacional (III). Finalmente, se apreciará la aplicabilidad de dichas iniciativas al caso mexicano y se propondrán una serie de disposiciones que podrían configurar un nuevo modelo de TBI para México (IV).

\section{LAS CAUSAS DE LA GRISIS DEL ACTUAL RÉGIMEN JURÍDICO INTERNACIONAL DE LOS TBI}

\section{El carácter desequilibrado de los acuerdos en favor de los inversionistas extranjeros}

En varias de las críticas expresadas en torno al actual régimen jurídico de los TBI resaltan los señalamientos de su carácter desequilibrado en favor de los inversionistas extranjeros - frecuentemente empresas multinacionales - y en contra de los Estados, en particular, tratándose de países en vía de desarrollo. ${ }^{13}$

La concepción del régimen de los TBI como una "esclavitud" en la que "todo está en contra de los Estados" y en favor de las multinacionales denuncia la propia lógica "protectora" de dichos tratados. Los TBI otorgan una serie de importantes derechos a los inversionistas extranjeros, pero no les imponen ningún tipo de obligaciones vinculantes. En efecto, dichos tratados establecen derechos sólo para los inversionistas y obliga-

13 Así por ejemplo, en 2017, el entonces presidente ecuatoriano Rafael Correa afirmó que: "No es cierto que (estos tratados) han atraído inversiones, y hubo mucha presencia de abusos (...) todo está en contra de los Estados, por lo que nos han llenado de juicios". En un discurso similar pronunciado en 2009 a la ocasión del retiro de Ecuador de la Convención de Washington, Correa señaló que dicho retiro era necesario "para la liberación de nuestros países, porque esto significa coloniaje, esclavitud frente a trasnacionales, frente a Washington, frente al Banco Mundial, y eso no lo podemos seguir tolerando" (Correa suscribe decreto que da por terminado convenio con el CIADI, http://wrere.eltiempo.com. ec/noticias/economia/1/211881/correa-suscribe-decreto-que-da-por-terminado-convenio-con-el-ciadi). 
ciones sólo para los Estados. Como lo señala Monheburrun (Monheburrun 2014, vol. 11, 204), una parte de la doctrina considera que el derecho internacional de las inversiones es una máquina de "empoderamiento", buscando sólo la protección de las inversiones y de los inversionistas e ignorando en este camino los intereses de otros actores que intervienen en los procesos relacionados con el funcionamiento de las IED (Sornarajah 2000, 9). En vez de ser bilaterales, los TBI serían caracterizados por una patente ausencia de reciprocidad y por un carácter más bien unilateral (Monheburrun 2014, vol. 11, 211). La relación jurídica que organizarían sería la de "amos" (inversionistas extranjeros) y "siervos" (Estados).

Existe otra muy importante crítica en contra del carácter desequilibrado del actual régimen de los TBI en favor de los inversionistas y en contra de los Estados. En virtud de la misma, habría un conflicto intrínseco entre la protección de los derechos reconocidos a los inversionistas extranjeros en los TBI y la capacidad soberana de los Estados de adoptar regulaciones normativas en asuntos de interés general.

En aplicación de las disposiciones de los TBI, se ha reconocido que uno de los componentes del estándar de "trato justo y equitativo" exige la protección de las "expectativas legítimas" que los inversionistas extranjeros tenían en el momento en el que se realizó su inversión (Técnicas Medioambientales Tecmed, S. A. vs. United Mexican States 2003, párrafo 154). Por lo tanto, si, posteriormente, el Estado modifica su marco regulatorio de una manera no prevista o esperada por el inversionista en el momento en el que se realizó la inversión, y si este cambio genera un costo económico para el inversionista, el Estado tiene que otorgarle una debida compensación por las pérdidas (Sociedad General de Aguas de Barcelona S.A. and InterAgua Servicios Integrales del Agua S.A. vs. Argentine Republic 2018, párrafo 207 y 122). Asimismo, la jurisprudencia arbitral en materia de inversiones ha establecido que si el Estado adopta un cambio en su legislación interna y éste provoca una pérdida económica para el inversionista, el Estado puede ser reconocido jurídicamente responsable frente al inversionista extranjero (Lise y Oleksandr 2016) por una "expropiación indirecta". Dicha forma de expropiación resultaría de una "interferencia sobre los derechos de propiedad del inversionista extranjero, de tal magnitud que deja dichos derechos inútiles, evitando su uso, goce o disposición" (Faya 2013, 221). 
La vaguedad del contenido del estándar de trato justo y equitativo y de las nociones de "expectativas legítimas" y "expropiación indirecta" ha permitido la adopción de interpretaciones muy extensivas de las mismas en la jurisprudencia de los tribunales arbitrales internacionales, con competencia en materia de inversiones (Valero 2016). ${ }^{14}$ Estos importantes antecedentes alimentan las vivas críticas en contra del actual régimen de los TBI porque crean la impresión, al menos aparente, que dicho régimen "otorga a los inversionistas extranjeros la posibilidad de contestar nada menos que cualquier línea de acción gubernamental que no les guste" (Dupré 2017).

\section{Las críticas al funcionamiento del arbitraje internacional} en materia de inversiones

La primera crítica al actual funcionamiento del arbitraje internacional en materia de inversiones concierne el diseño procesal de dicho medio de solución de controversias.

En efecto, la aplicación de las reglas contenidas en los TBI conduce a otorgar a los inversionistas extranjeros "un monopolio" en la capacidad de iniciar los procedimientos arbitrales. Dicho en otros términos, los inversionistas siempre son los demandantes y los Estados, la parte demandada en dichos procedimientos (Monheburrun 2014, vol. 11, 209). Por otro lado, la utilización de este mecanismo por parte de los inversionistas extranjeros ha conocido un pleno boom en las últimas décadas. En los principios de su desarrollo, dicho mecanismo había conducido a sentencias

14 En un polémico asunto reciente, la más grande empresa multinacional tabacalera impugnó, sobre la base de un TBI entre Uruguay y Suiza, una legislación uruguaya, destinada a proteger la salud pública de los efectos nocivos del tabaquismo. En asuntos similares, la empresa multinacional Veolia contestó el incremento del salario mínimo en Egipto (Veolia vs. Egipto (salario mínimo), caso pendiente ante un tribunal arbitral de CIADI) y la empresa energética sueca Vattenfall protestó en contra de la decisión de Alemania de renunciar al uso de energía nuclear (Jucio en Alemania al "cerrojazo" nuclear de Merkel, http:// wrere.elmundo.es/economia/2016/03/12/56e326fb22601dae268b45a5.html). Ambas empresas demandaron a los Estados ante tribunales arbitrales de inversiones, alegando la violación de "expectativas legítimas" y la adopción, por parte de los Estados, de medidas constitutivas de "expropiación indirecta". 
arbitrales obligatorias en muy pocas ocasiones. ${ }^{15}$ A partir de la década de los noventa, asistimos a una multiplicación, sin precedente, de demandas presentadas por empresas inversionistas en contra de Estados soberanos ante tribunales arbitrales internacionales.

Además, la percepción generalizada es que los Estados "siempre pierden y las empresas siempre ganan" en dichos procedimientos. Ciertamente esto no sucede en todos los casos, pero según datos de la ONU, al menos en $60 \%$ de las controversias, sometidas a tribunales arbitrales internacionales, los Estados han sido condenados a pagar algún tipo de indemnización a los inversionistas extranjeros por haber incumplido con obligaciones, derivadas de las disposiciones de un tratado de inversiones. Además, se trata de indemnizaciones millonarias. Recientemente en tres asuntos conexos Cour permanente d'arbitrage (2005a, 2005b y 2005c, en adelante CPA), un órgano arbitral constituido bajo los auspicios de la CPA condenó a Rusia a pagar a las empresas inversionistas la cantidad record de 50 mil millones de dólares.

A estas percepciones se suman otra serie de críticas más concretas hacia el actual funcionamiento del sistema de resolución de controversias en materia de inversiones. En primer lugar, se denuncia su falta de legitimidad. ${ }^{16}$ En segundo lugar, se apunta a la ausencia de transparencia de los procedimientos arbitrales internacionales en materia de inversiones Conférence des Nations Unies sur le Commerce et le Développement (2012, en adelante CNUCED). En tercer lugar, se denuncia la falta de coherencia en la jurisprudencia, emanada de los órganos arbitrales que resuelven controversias basadas en el derecho internacional de las inversiones. ${ }^{17}$ En cuarto lugar, se critica la falta de independencia e imparcialidad de los árbitros (CNUCED 2015, 5). Finalmente, se señalan los costos exorbitantes que un procedimiento arbitral en materia de inversiones puede representar para las finanzas públicas del Estado. El costo promedio de dicho procedimiento se sitúa alrededor de 3 millones de dólares y, frecuen-

15 Hasta 1995, soóo habían sido resueltos 3 casos contenciosos por medio de órganos arbitrales internacionales competentes en materia de inversiones.

16 Resulta difícil sostener la legitimidad que poseen tres árbitros — personas privadaspara contestar y revisar las políticas soberanas y públicas de los Estados.

17 La ausencia de un segundo grado de jurisdicción implica la imposibilidad de apelar una sentencia arbitral para corregir eventuales errores en la aplicación e interpretación de las reglas jurídicas aplicables en materia de inversiones. 
temente, aun si las empresas inversionistas pierden el fondo del litigio, los árbitros condenan a los Estados a cubrir las costas, creando así un peso importante para su erario público.

Las posturas cada vez más críticas hacia el mecanismo de resolución de controversias en materia de inversiones y hacia el régimen jurídico de los TBI han conducido a la adopción de varias propuestas de reforma. Dichas propuestas han sido debatidas en numerosos foros internacionales, en particular, en la Comisión de las Inversiones de la GNUCED, el Foro Mundial de las Inversiones y la OCDE. Asimismo, a partir de 2015, la Comisión de la Unión Europea propuso "establecer un órgano permanente para resolver los litigios relativos a las inversiones, abandonando el sistema ad hoc de resolución de litigios entre inversores y Estados". Sin embargo, la ausencia de una institución multilateral, con competencia universal en materia de inversiones, complica la adopción de iniciativas de reforma más amplias. Por lo tanto, muchos Estados miembros de la comunidad internacional han tomado en cuenta las críticas al actual régimen de protección internacional de las IED para adoptar, unilateralmente, nuevos modelos de TBI.

\section{LA ADOPGIÓN DE NUEVOS MODELOS DE TBI POR ALGUNOS ESTADOS MIEMBROS DE LA COMUNIDAD INTERNACIONAL}

\section{El modelo de India}

India se ha unido a las críticas actuales acerca del funcionamiento del régimen jurídico de los TBI y a las contestaciones que se formulan en contra del arbitraje internacional de inversiones. Esta postura del Gobierno indio se agudizó después de que este Estado perdiera el caso White Industries vs. India (Prabhash et al. 2018, 9). En 2016, India adoptó un nuevo modelo de TBI (Prabhash et al. 2018, 9), con el objetivo de "garantizar a los inversionistas extranjeros en India una eficaz protección jurídica" y "mantener un equilibrio entre los derechos de los inversionistas extranjeros y las obligaciones del gobierno" (Department of Economic Affairs s. d.). Consecuentemente, el gobierno indio notificó a 58 Estados (entre otros, el Reino Unido, Francia, Alemania y Suecia) con los que ha celebrado TBI que están por expirar, o expiran pronto, su intención de rene- 
gociar dichos acuerdos sobre la base del nuevo modelo. ${ }^{18}$ Asimismo, India proyecta utilizar su nuevo modelo de TBI para modificar los capítulos relativos a inversiones, contenidos en sus acuerdos de libre comercio (Prabhash et al. 2018, 10).

En cuanto a su contenido sustancial, el nuevo modelo de TBI de India, busca reequilibrar la relación jurídica entre el Estado y los inversionistas extranjeros, al otorgar más derechos al Estado y más obligaciones a los inversionistas. En ese sentido, el nuevo modelo de acuerdo abandona la definición amplia de "inversión" de los modelos anteriores para optar por una definición más estricta, basada en la noción de "empresa" ${ }^{19}$ De manera radical, el nuevo modelo de TBI de India suprime, además, al estándar de "trato justo y equitativo" de las disposiciones del acuerdo. ${ }^{20}$ Dicha disposición establece condiciones particularmente restrictivas para que el inversionista extranjero pueda comprobar la violación de las reglas de trato, garantizadas por el TBI. ${ }^{21}$ Además, por esta nueva concepción de la noción de "trato" se excluye la aplicación de la noción de "expectativas legítimas". Esto significa que aun si India, por medio de su conducta, crea expectativas legítimas para un inversionista extranjero y no las cumple, el

18 Adicionalmente, respecto a los restantes 25 Estados (China, Finlandia, Bangladesh y México, por ejemplo), India propuso la elaboración de opiniones de interpretación oficial conjunta (joint interpretive statements) que permitan a los propios Estados partes en el tratado aclarar cómo deben interpretarse sus disposiciones.

19 Conforme con el artículo 1 (4) del acuerdo, una inversión significa una empresa constituida, organizada y operando de buena fe, de conformidad con las leyes del Estado en el cual desempeña su actividad económica, incluyendo los bienes de la empresa, que tiene las características de una inversión, tales como la utilización de capital u otros recursos, cierta duración, la expectativa de ganancias y la asunción de riesgo, tomando en cuenta el significado de su actividad económica para el desarrollo del Estado en cuyo territorio se realiza la inversión.

20 El tratado contiene únicamente una cláusula, denominada "trato de las inversiones" que prohíbe a los Estados partes someter a los inversionistas extranjeros a tratos constitutivos de violaciones a normas de derecho internacional consuetudinario a través de: "a) denegación de justicia (...); b) violación fundamental del debido proceso; c) discriminación por motivos manifiestamente injustificados, basadas en criterios de género, raza o creencias religiosas, entre otros; d) trato manifiestamente abusivo, como, por ejemplo, coerción, coacción o abuso".

21 Así, si el inversionista pretende alegar la existencia de una violación del debido proceso, tiene que comprobar que se trata de una violación "fundamental"; asimismo, si intenta demostrar la existencia de discriminación, ha de corroborar que se trata de una discriminación "por motivos manifiestamente injustificados".

Esta obra está bajo una Licencia Creative Commons

Atribución-NoComercial-SinDerivar 4.0 Internacional, IIJ-UNAM.

Boletín Mexicano de Derecho Comparado, núm. 158, mayo-agosto de 2020, pp. 863-894. 
inversionista no podrá demandar al Estado ante un órgano arbitral internacional, sobre la base del TBI (Prabhash et al. 2018: 11).

Otra importante innovación del nuevo modelo de TBI indio consiste en re-introducir en sus disposiciones, la regla del agotamiento de los recursos internos ${ }^{22}$ y erigir así una "barrera procesal" casi impenetrable al recurso, por parte del inversionista, a un arbitraje internacional de inversiones. Adicionalmente, en cumplimiento de todos los requisitos establecidos en el artículo 15 del nuevo modelo de TBI de India, el plazo disponible para iniciar un procedimiento arbitral internacional en contra del Estado se reduce a alrededor de tres meses (Prabhash et al. 2018, nota $61,29)$.

\section{El modelo de los Países Bajos}

Holanda es uno de los principales países de origen de inversionistas extranjeros que inician procedimientos arbitrales en contra de otros paí-

22 En efecto, en virtud del artículo 15 del modelo, en caso de controversia entre el Estado y el inversionista extranjero, la persona privada tiene que litigar el caso ante los tribunales indios, por lo menos, por un periodo de 5 años, antes de poder "elevar" el conflicto en el plano de la justicia internacional y someterlo a un órgano arbitral internacional. Este periodo de 5 años comienza a correr a partir del momento en el que el inversionista obtenga conocimiento de "la medida en cuestión y del daño o perjuicio resultante de la misma para su inversión" o incluso "cuando debió de haber tenido conocimiento" de dicha medida por primera vez. La obligación de agotar los recursos internos solo deja de aplicarse si el inversionista demuestra que no "hay recursos disponibles" en el derecho interno del Estado para lograr una defensa a su causa. Una vez que termine el periodo de 5 años, el inversionista tiene que notificar al Estado su intención de llevar el caso ante un tribunal arbitral internacional. Esta notificación debe acompañarse de un periodo adicional de 6 meses durante el cual el Estado y el inversionista deben tratar de resolver su controversia por otros medios pacíficos, incluyendo las negociaciones, las consultas u otros mecanismos, sujetos a la intervención de un tercero imparcial. En virtud del artículo 15 del nuevo modelo de TBI, una vez que transcurra este periodo adicional, el inversionista puede iniciar el arbitraje internacional en contra de India si cumple con las siguientes condiciones limitativas: que no hayan pasado más de 6 años a partir del momento en el que el inversionista haya tenido o debió de haber tenido conocimiento de la medida estatal, al origen de la controversia; que no hayan transcurrido más de 12 meses a partir del término de los procedimientos internos; que antes de someter la controversia al tribunal arbitral, se haya otorgado, al menos, un plazo de 90 días al Estado; que el inversionista extranjero haya renunciado a su derecho de iniciar o continuar cualquier procedimiento, basado en el derecho interno del Estado". 
ses (Bart-Jaap y Roeline 2018). Consecuentemente, muchos países han mostrado su descontento respecto a la política demasiado "liberal" de los Países Bajos en materia de inversiones. Sudáfrica, Bolivia, India, Indonesia, Ecuador, Uganda o Venezuela, incluso, han anunciado su intención de retirarse de los TBI que han celebrado con este Estado. Esta situación llevó al gobierno holandés a elaborar, en 2018, un nuevo modelo de TBI que debería ser utilizado para la renegociación de los 79 TBI celebrados con países no miembros de la UE (Bart-Jaap y Roeline 2018).

El nuevo modelo de TBI holandés mantiene una definición muy amplia de "inversión", ${ }^{23}$ pero, al mismo tiempo, busca restringir la definición de "inversionista extranjero". ${ }^{24}$ Dicho modelo también se propone encuadrar las hipótesis en las que un inversionista extranjero pueda sostener la existencia de medidas de expropiación indirecta. ${ }^{25}$ En su artículo 9o., el texto del nuevo modelo, incluye una referencia al "estándar de trato justo y equitativo" y establece una lista de ejemplos de tratos violatorios de di-

23 En virtud del artículo 1o. del modelo, es inversión "todo tipo de fondo (...) que incluya cierta duración, y cuenta con la asignación de capital u otros recursos, la expectativa de ganancias y la asunción de un riesgo (...)." Asimismo, dicho artículo incluye una serie de ejemplos de inversión, entre otros, basados en derechos de propiedad mobiliaria o inmobiliaria, derechos derivados de la tenencia de bonos, acciones u otro tipo de activos de empresas, derechos en el ámbito de la propiedad intelectual, o derechos otorgados en virtud de normas de derecho público o en virtud de un contrato para explorar, explotar o extraer recursos naturales".

24 El artículo 1o. del modelo establece que la persona moral que desee beneficiarse de la protección del tratado deberá demostrar que "es una persona moral constituida según las leyes de uno de los Estados contratantes y que desarrolla actividades de negocio sustantivas en el territorio de este Estado (...)". Más adelante, el artículo precisa qué debe entenderse por "actividades comerciales sustanciales". Entre otros; "tener una oficina o la administración establecida en un Estado contratante, un número de empleados en ese Estado, una actividad productiva o un laboratorio de investigación, establecido en dicho Estado".

25 En virtud del artículo 2-2 del texto: "Las disposiciones del acuerdo no limitarán el derecho de las partes contratantes de adoptar regulaciones en sus territorios, con el fin de lograr objetivos legítimos, como, por ejemplo, la protección de la salud pública, la seguridad, el medio ambiente, la moral pública, derechos laborales, bienestar animal, la protección social o de los consumidores o por motivos financieros prudentes. El simple hecho de que una parte contratante adopte medidas regulatorias, incluso a través de la modificación de sus leyes, que afecten negativamente a la inversión o interfieran con las expectativas del inversionista, incluyendo sus expectativas de ganancias, no constituye una violación de una de las obligaciones del Estado en virtud del acuerdo". 
cho estándar, que son los mismos que los previstos en el TBI de India. ${ }^{26} \mathrm{~A}$ diferencia del modelo indio, el artículo 9o. del modelo holandés también consagra la protección de las "expectativas legítimas" del inversionista.

El nuevo modelo de TBI de los Países Bajos incluye una sección entera dedicada al "Desarrollo sostenible". En virtud del artículo 6o. del modelo, cada parte contratante se compromete a promover el desarrollo de las inversiones extranjeras en una forma compatible con los objetivos del desarrollo sostenible. En el mismo sentido, el nuevo modelo reafirma, expresamente, el compromiso de las partes contratantes con las obligaciones que les incumben en virtud de los acuerdos multilaterales aplicables a la protección internacional del medio ambiente, a la cautela de los derechos laborales y de los derechos humanos de los cuales son partes. Adicionalmente, el acuerdo reafirma la obligación de debida diligencia al cargo de los inversionistas en identificar, prevenir, mitigar y tomar en cuenta los riesgos e impactos sociales y ambientales de su inversión y establece su obligación de respetar las leyes internas del Estado huésped en materia de protección del medio ambiente, protección de los derechos humanos y de los derechos laborales.

La sección 5 del nuevo modelo está expresamente dedicada a la resolución de controversias entre un Estado parte en el acuerdo y un inversionista del otro Estado miembro del mismo. ${ }^{27}$ La principal innovación procesal respecto al funcionamiento del arbitraje internacional de inversiones concierne el procedimiento de nombramiento de los árbitros. En efecto, en el artículo 20 del mismo se establece que los árbitros no serán nom-

26 Entre otros, se trata de la denegación de justicia, violaciones fundamentales al debido proceso, arbitrariedad manifiesta, discriminación sobre la base de género, raza, nacionalidad, orientación sexual o creencias religiosas, coerción, abuso, prácticas de corrupción o semejantes conductas de mala fe.

27 El primer artículo 15 de la Sección se intitula "Corte Multilateral de Inversiones" y establece que esta sección del acuerdo dejará de aplicarse una vez que entre en vigor entre las partes un Acuerdo internacional respecto a la creación de una Corte Multilateral, competente para resolver controversias originadas en la aplicación e interpretación del acuerdo. Las otras disposiciones de esta parte del acuerdo retoman, en lo esencial, las disposiciones de los TBI clásicos en la materia. En este sentido, el nuevo modelo holandés establece un recurso al arbitraje internacional, bajo los auspicios del CIADI o un arbitraje internacional ad hoc, con aplicación del Reglamento de Arbitraje de la CNUDMI o con la posibilidad de que los procedimientos sean administrados por la CPA. 
brados directamente por las partes en la controversia, como normalmente ocurre, sino que serán nombrados por una autoridad distinta. ${ }^{28}$

\section{LA ADOPCiÓN DE UN NUEVO MODELO DE TBI PARA MÉXICO}

\section{Modificar la definición de inversión extranjera}

La definición de inversión extranjera en los TBI de México es sumamente amplia y generalmente se basa en lo establecido al respecto en el artículo 1139 del TLCAN. Dicha definición es retomada casi literalmente en el último TBI de México con Emiratos Árabes Unidos. ${ }^{29}$

28 Estas autoridades son el Secretario General del CIADI, para los procedimientos que se celebren bajo los auspicios de este Centro, o el Secretario General de la CPI para los arbitrajes regidos por el Reglamento de Arbitraje de la CNUDMI (artículo 20 del acuerdo).

29 En virtud de la misma: "inversión significa cualquiera de los siguientes activos propiedad de inversionistas de una Parte Contratante o controlados por éstos y establecidos o adquiridos de conformidad con las leyes y reglamentos de la otra Parte Contratante en cuyo territorio se efectúa la inversión: (a) una empresa; (b)acciones, partes sociales y otras formas de participación en el capital de una empresa; (c) instrumentos de deuda de una empresa: (i) cuando la empresa es una filial del inversionista, o (ii cuando la fecha de vencimiento original del instrumento de deuda sea por lo menos de tres (3) años, sin incluir instrumentos de deuda de una Parte Contratante o de una empresa del Estado, independientemente de la fecha original de vencimiento; (d) un préstamo a una empresa: (i) cuando la empresa es una filial del inversionista, o (ii)cuando la fecha de vencimiento original del préstamo sea por lo menos de tres (3) años, sin incluir préstamos a una Parte Contratante o a una empresa del Estado independientemente de la fecha original de vencimiento; (e) bienes raíces u otras propiedades, tangibles o intangibles, adquiridos o utilizados con el propósito de obtener un beneficio económico o para otros fines empresariales; (f) la participación que resulte de la obligación de comprometer capital u otros recursos en el territorio de una Parte Contratante destinados al desarrollo de una actividad económica en dicho territorio, tales como los derivados de: (i) contratos que involucran la presencia de la propiedad de un inversionista en el territorio de la otra Parte Contratante, incluidos, los contratos de llave en mano o de construcción, o concesiones; (ii) contratos donde la remuneración depende sustancialmente de la producción, ingresos o ganancias de una empresa, o (iii) concesiones comerciales otorgadas por ley o por contrato, relacionadas con hidrocarburos, las cuales se regirán conforme a los términos y condiciones de las mismas acordados entre el inversionista y la Parte Contratante o la subdivisión política de la Parte Contratante, cuando sea aplicable, en cuyo territorio se efectúan dichas concesiones; (g) reclamaciones pecuniarias relativas a los tipos de intereses dispuestos en los incisos (a) a (f) anteriores, sin incluir reclamaciones pecuniarias derivadas exclusivamente de: (i) contratos comerciales para la venta de bienes o servicios por un nacional o empresa en el territorio

Esta obra está bajo una Licencia Creative Commons

Atribución-NoComercial-SinDerivar 4.0 Internacional, IIJ-UNAM.

Boletín Mexicano de Derecho Comparado, núm. 158, mayo-agosto de 2020, pp. 863-894. 
La definición extremadamente amplia de inversión extranjera directa ha sido una de las principales causas para que México perdiera los casos en los que fue demandado por empresas multinacionales ante órganos arbitrales internacionales, sobre la base de un tratado de inversiones. Así, por ejemplo, en el caso Cargill (Cargill vs. México, 2009), una empresa estadounidense que demandó a México por daños sufridos respecto a una actividad económica desarrollada en el territorio de Estados Unidos. El tribunal arbitral consideró que: "la definición de "inversión" del artículo 1139 es amplia e inclusiva" y permite cubrir las actividades de Cargill en Estados Unidos. México fue condenado a pagar una indemnización de 77.3 millones de dólares, más intereses, a la empresa, y, adicionalmente, tuvo que cubrir las costas del arbitraje.

La posibilidad de limitar los recursos, en contra de México, por parte de una empresa que no opera en el territorio mexicano, ya está prevista en el último TBI con Emiratos Árabes Unidos. En efecto, en respuesta directa al antecedente del caso Cargill, el artículo 11-1 del acuerdo establece que:

Un inversionista de una Parte Contratante podrá someter una reclamación a arbitraje en el sentido de que la otra Parte Contratante ha incumplido una obligación establecida en el Capítulo II, y que el inversionista ha sufrido pérdida o daño en virtud de ese incumplimiento o como consecuencia de éste. Para mayor certeza, cuando un inversionista de una Parte Contratante someta una reclamación a arbitraje puede recuperar sólo la pérdida o daños en que ha incurrido en su calidad de un inversionista de una Parte Contratante.

Por su parte, en virtud de la definición de "inversionista extranjero", éste debe ser "una empresa (...) que tenga operaciones sustantivas de ne-

de una Parte Contratante a una empresa en el territorio de la otra Parte Contratante, o (ii) el otorgamiento de crédito en relación con una transacción comercial, como el financiamiento al comercio, que no se refiera al préstamo cubierto por las disposiciones del inciso (d) anterior, y (h)derechos de propiedad intelectual, incluyendo pero no limitado a derechos de autor y los derechos conexos, las patentes, los diseños industriales, know-how, marcas, secretos industriales y de negocios, nombres comerciales, indicaciones geográficas y esquemas de trazado (topografías) de circuitos integrados y los derechos sobre variedades vegetales; tal como se define o se hace referencia en el Acuerdo sobre los Aspectos de los Derechos de Propiedad Intelectual relacionados con el Comercio de la Organización Mundial del Comercio". 
gocios en el territorio de esta parte contratante" y además, se recalca, que la empresa debe haber "realizado una inversión en el territorio de la otra parte contratante".

La inclusión de la obligación, para los inversionistas extranjeros, de tener "operaciones sustantivas de negocios" en México sigue la lógica del nuevo modelo de TBI de Holanda y busca limitar la posibilidad, para las empresas multinacionales, de librarse al treaty shopping. No obstante, la simple inclusión de la noción de "operaciones sustantivas de negocios" es insuficiente, porque deja una gran margen de maniobra a los árbitros internacionales que tendrán que interpretarla a la hora de resolver un litigio surgido de la aplicación del acuerdo. Por lo tanto, se sugiere precisar en el texto del nuevo modelo de TBI de México qué debe entenderse por "operaciones sustantivas de negocios en el territorio de un Estado: entre otros, "tener una oficina o un centro de administración, establecido en un Estado contratante, un número de empleados en ese Estado, una actividad productiva o un laboratorio de investigación, con sede en dicho Estado".

Adicionalmente, la definición de inversionista extranjero en el TBI entre México y los Emiratos Árabes Unidos debería complementarse con una revisión de la definición extremadamente amplia de inversión extranjera porque ésta puede permitir a un tribunal arbitral internacional, constituido con fundamento en sus disposiciones, otorgar una protección jurídica a empresas que no tienen utilidad económica en el territorio mexicano. Por lo tanto, se recomienda tomar en consideración la definición de "inversión", prevista en los nuevos modelos de TBI de India y de Holanda y se sugiere la inclusión de un artículo con la siguiente redacción: "una inversión significa una empresa constituida, organizada y operando de buena fe, de conformidad con las leyes del Estado en el cual desempeña sus actividades comerciales sustanciales, incluyendo los bienes de la empresa, que tienen las características de una inversión, tales como la utilización de capital u otros recursos, cierta duración, la expectativa de ganancias y la asunción de riesgo". ${ }^{30} \mathrm{El}$ objetivo de esta modificación con-

30 Una opción más minimalista consistiría en seguir utilizando la definición de "inversión" insertada en el TBI con Emiratos Árabes Unidos, pero modificarla para restringirla en cuanto a los requisitos económicos de la inversión. En este sentido, podría tomarse en consideración la definición utilizada en el TLC entre Canadá y la UE (conocido como el CETA). Dicha definición es casi idéntica a la empleada en el TBI de México con Emiratos Árabes Unidos, pero, se prevén, adicionalmente, criterios restrictivos en cuanto a las 
siste en limitar la protección jurídica, ofrecida por el TBI, a operaciones que verdaderamente se desarrollen en el territorio mexicano y representen un beneficio para la economía interna de México.

\section{La inclusión de un capitulo sobre "Desarrollo sostenible"}

Se recomienda tomar en consideración el modelo de TBI holandés e incluir en el nuevo modelo de TBI de México un capítulo sobre "Desarrollo sostenible". Se sugiere que en dicho capítulo se incluyan disposiciones referentes a la protección de los objetivos del desarrollo sostenible, en el respeto de las leyes internas y de las normas de derecho internacional aplicables en la materia. Así, por ejemplo, el nuevo modelo de TBI mexicano podría establecer que "cada parte contratante se compromete a promover la realización de las inversiones extranjeras en una forma compatible con los objetivos del desarrollo sostenible". En segundo lugar, se sugiere la inclusión de obligaciones directas para los inversionistas extranjeros respecto a la prevención y reparación de daños ambientales, susceptibles de ser ocasionados por su actividad económica en el territorio mexicano. En particular, el nuevo modelo de TBI podría enunciar que: "los inversionistas extranjeros se obligan a respetar las leyes mexicanas y los tratados celebrados por México en materia de protección del medio ambiente" y prever que: "los inversionistas adquieren un deber de debida diligencia para prevenir, evitar y mitigar el impacto ambiental de su inversión en el territorio de una de las partes contratantes".

La razón de la inclusión de dichas disposiciones radica, en primer lugar, en los aprendizajes obtenidos de los casos en los que México ha sido demandado por empresas multinacionales ante tribunales arbitrales internacionales, con competencia en materia de inversiones.

En el caso Abengoa vs. Estados Unidos Mexicanos (2013), una empresa multinacional española demandó a México por la cancelación de la licencia de operación de una planta de tratamiento de residuos industriales

características económicas de la inversión, en particular, se exige que ésta, en todo caso, implique "la asignación de capital u otros recursos, la expectativa de ganancias y la asunción de riesgo". 
peligrosos en el municipio de Zimapán, Hidalgo. ${ }^{31}$ El municipio sostuvo que: "a) Ia Licencia de Funcionamiento contraviene el derecho constitucional a disfrutar de un medioambiente adecuado (...)". Este argumento no fue discutido por los árbitros internacionales en el procedimiento que la empresa multinacional inició en contra de México ante el CIADI (TNI s. d.). El tribunal arbitral desarrolló una interpretación estricta del TBI entre México y España que no contenía ningún tipo de disposiciones referentes a la protección del medio ambiente. Asimismo, consideró que "no existe ninguna evidencia de que la planta pudiera comportar algún riesgo para la salud pública" (Abengoa S.A. y Cofides S.A. vs. Estados Unidos Mexicanos 2013, párrafo 619). A pesar de que la inversión inicial de la empresa multinacional fue de 12 millones de dólares, los contribuyentes mexicanos fueron condenados a pagar 45 millones de dólares de indemnización (el equivalente a 3 veces el PIB anual del estado de Hidalgo) (TNI s. d.). De manera similar, en el caso Metalclad Corporation vs. Estados Unidos Mexicanos (1997), una empresa estadounidense introdujo una demanda en contra de México ante un tribunal arbitral internacional constituido sobre la base del capítulo XI del TLCAN, alegando que el rechazo de un permiso de construcción de una planta de tratamiento de residuos peligrosos por un municipio del estado de San Luis Potosí era equivalente a una expropiación indirecta. De nueva cuenta, los árbitros no apreciaron el impacto de la actividad económica del inversionista extranjero en materia de protección del medio ambiente y se apegaron a las disposiciones del TLCAN en materia de inversiones que no establecían ningún tipo de obligaciones al cargo del inversionista en materia de promoción de los objetivos del desarrollo sostenible. La indemnización acordada al inversionista fue de 16.7 millones de dólares. En el caso Técnicas Medioambientales Tecmed vs. Estados Unidos Mexicanos (2001), una empresa española inició un arbitraje internacional en contra de México sobre la base del TBI entre México y España, sosteniendo que había sido víctima de una expropiación indirecta, como consecuencia de la negativa por el Instituto Nacional de Ecología de renovar su autorización para operar una planta de confinamiento de residuos peligros. En este caso tampoco se apreció el cumplimiento, por parte del inversionista, de las leyes mexicanas y de los

31 Dicha planta había sido instalada a 2 kilómetros de una reserva natural y a menos de 500 metros de la comunidad indígena hñañu.

Esta obra está bajo una Licencia Creative Commons

Atribución-NoComercial-SinDerivar 4.0 Internacional, IIJ-UNAM.

Boletín Mexicano de Derecho Comparado, núm. 158, mayo-agosto de 2020, pp. 863-894. 
tratados internacionales en materia de protección del medio ambiente. ${ }^{32}$ La indemnización otorgada a la empresa inversionista fue de 5.5 millones de dólares.

Otra razón por considerar la inclusión de disposiciones relativas a las obligaciones de las empresas de prevenir y mitigar los posibles daños ambientales que cause su actividad económica tiene que ver con los impactos ambientales de algunas inversiones extranjeras en el sector energético mexicano. Así, por ejemplo, distintas empresas, en particular, canadienses, extraen recursos naturales en México por medio del fracking que produce efectos nefastos para el medio ambiente.

Sin una regulación clara de la relación entre la protección de las IED y la protección del medio ambiente, el actual modelo de TBI mexicano seguirá sirviendo de base legal para que inversionistas extranjeros que desarrollen actividades, susceptibles de causar un daño ambiental de gran envergadura en el territorio nacional, gocen de importantes derechos, pero no sean deudores de ningún tipo de obligaciones convencionales de prevenir o mitigar el impacto ambiental de dichas actividades. La atracción de las IED, en ningún caso, debe seguir justificando la degradación de los recursos naturales de México y la producción de daños ambientales, en la mayoría de los casos, irreparables.

\section{Limitar el alcance del estándar de "trato justo y equitativo" y de la noción de "expectativas legítimas"}

Se sugiere limitar el alcance del estándar de "trato justo y equitativo", por el de una enumeración limitativa en el texto del nuevo modelo de TBI, de conductas y medidas estatales, susceptibles de constituir un trato

32 En sus alegatos México sostuvo que la denegación del permiso, hecha por una autoridad nacional "es un acto regulatorio dictado dentro del marco de los poderes de policía del Estado en el contexto altamente regulado y particularmente delicado de la protección del medio ambiente y de la salud de la población. Los árbitros consideraron "que no se establece" que las actividades de la empresa "comprometan la salud pública o perjudiquen el equilibrio ecológico o la protección del medio ambiente, o que sean la causa de una genuina crisis social." Esta conclusión fue realizada sin que se entrara en un examen a fondo de los efectos potenciales de la actividad del inversionista sobre el medio ambiente y sin que se tomara en cuenta la obligación del operador económico de ejercer un deber de debida diligencia para evitar que su inversión dañe al medio ambiente. 
injusto e inequitativo. En este sentido, se podría recurrir a las disposiciones de los nuevos modelos de TBI de India y Holanda para prohibir a los Estados partes someter a los inversionistas extranjeros a tratos constitutivos de violaciones de normas de derecho internacional consuetudinario mediante: "a) denegación de justicia; b) violación fundamental del debido proceso; c) discriminación por motivos manifiestamente injustificados, basadas en criterios de género, raza o creencias religiosas, entre otros; d) trato manifiestamente abusivo, como, por ejemplo, coerción, coacción o abuso; c) actos de corrupción...".

Es de señalarse que el último TBI de México, celebrado con Emiratos Árabes Unidos, ya limita el significado del estándar de trato justo y equitativo, al equipararlo con el del estándar de trato mínimo a los extranjeros, reconocido en el derecho internacional consuetudinario. ${ }^{33}$ México tradicionalmente ha argumentado que el estándar de trato justo y equitativo no puede ir más allá que el estándar de trato mínimo de los extranjeros reconocido en el derecho internacional consuetudinario. La jurisprudencia arbitral en materia de inversiones ha considerado que "son actos que darían lugar a una violación del nivel mínimo de trato (...) y el derecho consuetudinario internacional aquellos que, sopesados en relación con el contexto de los hechos de que se trate, representan una repugnante denegación de justicia o una arbitrariedad manifiesta, que caigan por debajo de los niveles internacionalmente aceptables (International Thunderbird Gaming Corporation vs. los Estados Unidos Mexicanos 2006, párrafo 194).

No obstante, el verdadero problema tanto del estándar de trato mínimo a los extranjeros, como del de trato justo y equitativo es su vaguedad y la dificultad para determinar su contenido normativo. Como atinadamente lo señaló el tribunal arbitral en el caso El Paso vs. Argentina (El Paso Energy International Company vs. The Argentine Republic 2011), "el contenido del estándar de trato mínimo del derecho internacional está tan vagamente definido como el estándar de trato justo y equitativo (...)” (El

33 En virtud del artículo 4o. del acuerdo: "1. Cada Parte Contratante otorgará a las inversiones de inversionistas de la otra Parte Contratante, trato acorde con el derecho internacional consuetudinario, lo que incluye trato justo y equitativo, así como protección y seguridad plenas. 2. Para mayor certeza: (a) los conceptos de "trato justo y equitativo" y "protección y seguridad plenas" no requieren un trato adicional al requerido por el nivel mínimo de trato a los extranjeros propio del derecho internacional consuetudinario, ni que vaya más allá de éste, y $(\ldots)$ ". 
Paso Energy International Company vs. The Argentine Republic 2011, párrafo 335). Por lo tanto, si México mantiene en sus TBI una referencia al estándar de trato mínimo a los extranjeros en el derecho internacional consuetudinario, se corre el riesgo de que los árbitros internacionales vuelvan a interpretarlo de una manera extensiva. Sería preferible, en todo caso, definir expresamente en el tratado, qué actos u omisiones del Estado pueden considerarse como violatorias al trato mínimo de los extranjeros y, por ende, al trato justo y equitativo.

Asimismo, se sugiere eliminar cualquier referencia a la noción de "expectativas legítimas" de los inversionistas extranjeros del cuerpo del tratado. En este sentido, el TBI entre México y Emiratos Árabes Unidos ya excluye dicha noción del contenido de sus disposiciones. Es de recordarse que en el caso Tecmed, se desarrolló una noción demasiada amplia del concepto de "expectativas legítimas" del inversionista que no corresponde al estado de desarrollo del derecho internacional en esta materia. ${ }^{34}$ Dicha noción ha permitido a los árbitros, llevar la protección ofrecida a los inversionistas mucha más allá que los términos del tratado cuando: "en principio, las obligaciones del Estado receptor hacia los inversionistas extranjeros derivan de los términos del tratado de inversión aplicable y no de algún conjunto de expectativas que los inversionistas puedan tener o reclamar" (El Paso Energy International Company vs. The Argentine Republic 2011, párrafo 335). Así, por ejemplo, en los casos Gemplus S. A., SLP S. A. y Gemplus Industrial S. A. de C. V. y Talsud S. A. vs. los Estados Unidos Mexicanos (Gemplus S. A., SLP S. A., Gemplus Industrial S.A. de G.V. vs. The United Mexican States 2010), dos empresas argentinas demandaron a México sobre la base del TBI entre México y Argentina, denunciando que la revocación de una concesión del servicio público había violado las expectativas legítimas del inversionista (Gemplus S. A., SLP S.A., Gemplus

\footnotetext{
34 En particular, el tribunal consideró que: "Brindar un tratamiento a la inversión extranjera que no desvirtúe las expectativas básicas en razón de las cuales el inversor extranjero decidió realizar su inversión. Como parte de tales expectativas, aquél cuenta con que el Estado receptor de la inversión se conducirá de manera coherente, desprovista de ambigüedades y transparente en sus relaciones con el inversor extranjero, de manera que éste pueda conocer de manera anticipada, para planificar sus actividades y ajustar su conducta, no sólo las normas o reglamentaciones que regirán tales actividades, sino también las políticas perseguidas por tal normativa y las prácticas o directivas administrativas que les son relevantes. (...)" (Caso Tecmed, párrafo 154).
} 
Industrial S. A. de C. V. vs. The United Mexican States 2010, párrafos 5-7). ${ }^{35} \mathrm{El}$ tribunal consideró que las medidas gubernamentales habían sido "manifiestamente irracionales, arbitrarias y perversas, y dirigidas de mala fe contra las demandantes y sus derechos como inversionistas en virtud de los dos TBI". Por lo tanto, estimó que se habían violado las expectativas legítimas de los inversionistas. México fue condenado a pagar una indemnización a las dos empresas de 4,5 millones de dólares y de 6, 4 millones de dólares, respectivamente.

En vista de lo anterior, resulta urgente modificar las disposiciones de los TBI de México que incluyen referencias al "estándar de trato justo y equitativo" y a la noción "expectativas legítimas" de los inversionistas. La misma consideración es válidas tratándose del concepto de "expropiación indirecta".

\section{Restringir los casos en los que las modificaciones de leyes internas} pueden constituir una "expropiación indirecta"

A la protección que los TBI de México ofrecen a los inversionistas extranjeros en cuanto a la "expropiación directa" se suma la indemnización que éstos pueden obtener por una indemnización indirecta. Como fue señalado anteriormente, la noción de expropiación indirecta es una de las más criticadas en la actualidad porque permite a un inversionista extranjero atacar cualquier medida gubernamental que interfiera negativamente con sus intereses y derechos económicos.

La existencia de una "expropiación indirecta" ha sido invocada con mucha frecuencia en los casos iniciados en contra de México ante tribunales arbitrales internacionales. Así, por ejemplo, en el caso Metalclad, los árbitros consideraron que la adopción de un decreto por parte del gobernador del estado de San Luis Potosí que declaró reserva ecológica

35 Según los árbitros: “En el preámbulo de los TBI, México se obligó a proporcionar a) condiciones favorables para las inversiones argentinas (TBI de la Argentina) y b) crear condiciones favorables para las inversiones francesas (TBI de Francia). Con respecto a las expectativas del inversionista, la doctrina ha observado que: Las expectativas legítimas del inversionista se fundarán en [un] marco legal claramente perceptible y en los compromisos y declaraciones formulados expresa o implícitamente por el Estado receptor. El retiro por parte del Estado receptor de las garantías ofrecidas por éste que originaron las expectativas legítimas, violará el principio de trato justo y equitativo". 
la zona donde se ubica un confinamiento de residuos peligrosos, operado por la empresa Metalclad constituía una expropiación indirecta de su inversión (Metalclad Corporation vs. The United Mexican States 1997, párrafo 103). ${ }^{36}$ En el mismo sentido, en 2001, tres empresas estadounidenses productoras de jarabe de maíz de alta fructosa - Archer Daniels Midland Company y Tate \& Lyle Ingredients Americas, INC., Corn Products International, ING. y Cargill- demandaron a México ante el CIADI, alegando que la modificación de una la ley interna mexicana era constitutiva de una expropiación indirecta (Cargill vs. México 2009) (Archer Daniels Midland Company and Tate \& Lyle Ingredients Americas, Inc. vs. The United Mexican States 2007). Adicionalmente, México ha sido demandado por expropiación indirecta en los casos Azinian (Robert Azinian, Kenneth Davitian y Ellen Baca vs. Estados Unidos Mexicanos 1999), Feldman (Marvin Feldman vs. Estados Unidos Mexicanos 2002, 16), Waste Management (Marvin Feldman vs. Estados Unidos Mexicanos 2004) y los casos ya comentados Gemplus (Gemplus S. A., SLP S. A., Gemplus Industrial S. A. de C. V. vs. The United Mexican States 2010), Tecmed (Técnicas Medioambientales Tecmed, S. A. vs. The United Mexican States 2001) y Abengoa (Abengoa S. A. y Cofides S. A. vs. Estados Unidos Mexicanos 2013).

Es recomendable y urgente incluir en el nuevo modelo de TBI de México, disposiciones que permitan limitar y encuadrar la posibilidad para los inversionistas extranjeros de atacar medidas gubernamentales, adoptadas con base en el interés público general. En todo caso, es necesario que el nuevo modelo de acuerdo afirme el derecho legítimo del Estado receptor de las inversiones de adoptar todo tipo de medidas para regular asuntos de interés público. Los inversionistas extranjeros sólo deberían poder invocar una expropiación indirecta si dichas medidas no son adoptadas o implementadas de buena fe o si no resultan violatorias de las garantías de consistencia, transparencia y no discriminación. Los TBI de México no pueden seguir suponiendo la inmutabilidad del orden jurídico interno "y

36 En términos de los árbitros: "expropriation under NAFTA includes not only open, delibérate and acknowledged takings of property, such as outright seizure or formal or obligatoty transfer of title in favour of the host State, but also covert or incidental interference with the use of property which has the effect of depriving the ownei; in whole or in significant part, of the use or reasonably-to-be-expected economic benefit of property even if not necessarily to the obvious benefit of the host State" (caso Metalclad, párrafo 103). 
jugar el papel de una cláusula de estabilización específicamente diseñada en beneficio de los inversores extranjeros con los que el Estado ha firmado acuerdos de inversión" (El Paso Energy International Company vs. The Argentine Republic 2011, párrafo 368).

Por lo tanto, se sugiere la utilización de la redacción empleada en el nuevo modelo de TBI de Holanda para establecer que: "El simple hecho que una parte contratante adopte medidas regulatorias, incluso a través de la modificación de sus leyes, que afecten negativamente a la inversión o interfieran con las expectativas del inversionista, incluyendo sus expectativas de ganancias, no constituye una violación de una de las obligaciones del Estado en virtud del acuerdo". Asimismo, es necesario complementarla con una fórmula, derivada de la Third Restatement of the Foreign Relations Law of United States 1987 (Ley de Relaciones Extranjeras de los Estados Unidos, Tercera Enmienda 1987) para establecer que: "El Estado no es responsable de la pérdida de bienes u otras desventajas económicas derivadas de la aplicación de buena fe de leyes internas u otro tipo de medidas de este tipo que sean comúnmente aceptados como parte del poder de policía de los Estados, si no son discriminatorios, irrazonables o arbitrarias". Así, correspondería a los inversionistas extranjeros demostrar que la legislación interna mexicana es aplicada de manera discriminatoria, irrazonable o arbitraria. Esto permitiría recobrar la soberanía normativa de México y evitar que se tenga que indemnizar una afectación al bienestar (económico) de un inversionista extranjero para poder proteger el bienestar general. Como lo manifestaron los árbitros en el caso Saluka: "Existe hoy consenso en el derecho internacional, en el sentido de que los Estados no son responsables por el pago de indemnización a un inversor extranjero cuando, en ejercicio de sus facultades regulatorias ordinarias, adoptan una norma no discriminatoria de buena fe que persigue el bienestar general” (Saluka Investments BV vs. La República Checa 2006, párrafo 255).

\section{Modificar las disposiciones relativas al acceso de los inversionistas extranjeros a un arbitraje internacional}

Se recomienda tomar en cuenta los fundamentos de las críticas al arbitraje internacional de inversiones y limitar, en un nuevo modelo de TBI, 
la posibilidad de los inversionistas extranjeros de recurrir a este mecanismo ad hoc de solución de controversias.

Es de señalarse que el último TBI celebrado con los Emiratos Árabes Unidos ya establece algunos límites temporales al sometimiento de la controversia, por parte de un inversionista extranjero, a un arbitraje internacional de inversiones. ${ }^{37}$

Se sugiere que en el nuevo modelo de tratado se amplíen dichos límites para dar la oportunidad al Estado de lograr una resolución pacífica de la controversia antes del inicio del arbitraje internacional. Por lo tanto, se recomienda incluir un artículo que establezca lo siguiente: "Con el objeto de resolver la controversia de forma amistosa por otros medios pacíficos, incluyendo las negociaciones, las consultas u otros mecanismos, sujetos a la intervención de un tercero imparcial, el inversionista contendiente notificará por escrito a la Parte Contratante contendiente su intención de someter una reclamación a arbitraje cuando menos ocho (8) meses antes de que la reclamación sea presentada".

Asimismo, se sugiere incluir en el nuevo modelo de TBI de México, el contenido del artículo 11-8 del TBI con los Emiratos Árabes Unidos, con el objetivo de fijar un periodo máximo de tres años para introducir una demanda en contra del Estado ante un tribunal arbitral internacional, que cuente a partir de la fecha en la que el inversionista tuvo o debió de haber tenido conocimiento de los hechos que dieron origen a la controversia. También se recomienda que el nuevo modelo incluya la cláusula fork in tne road, ya insertada en el artículo 11-10 del TBI con Emiratos Árabes Unidos. ${ }^{38}$ Esto reduciría significativamente la posibilidad para las empresas inversionistas de desarrollar estrategias judiciales en múltiples foros de so-

37 Así, por ejemplo, el artículo 10-2 del acuerdo establece que: "Con el objeto de resolver la controversia de forma amistosa, el inversionista contendiente notificará por escrito a la Parte Contratante contendiente su intención de someter una reclamación a arbitraje cuando menos seis (6) meses antes de que la reclamación sea presentada”. Asimismo, en virtud del artículo 11-8 del acuerdo: "8. Una controversia podrá ser sometida a arbitraje dentro de los siguientes tres (3) años a partir de la fecha en que el inversionista o la empresa de la Parte Contratante contendiente, que es una persona moral que el inversionista posee o controla, tuvo conocimiento por primera vez o debió haber tenido conocimiento de los hechos que dieron lugar a la controversia".

38 Según dicha disposición: "Si el inversionista o una empresa propiedad del inversionista o controlada por éste presenta la controversia referida en los párrafos 1 ó 2 anteriores ante un tribunal administrativo o judicial competente de la Parte Contratante, la misma 
lución de controversias, para así obligar al Estado a desperdiciar recursos y tiempo para responder a sus estrategias de litigio.

Adicionalmente, se sugiere que se considere la posibilidad de que las partes, mediante un mutuo acuerdo, decidan que los árbitros sean nombrados por una autoridad neutral, por ejemplo, por la Secretaría del CIADI. ${ }^{39}$ De esta manera, se lograrían evitar los posibles conflictos de intereses de los árbitros y preservar al máximo su necesaria independencia e imparcialidad.

Finalmente, también se recomienda que el nuevo modelo de tratado regule cuestiones de ética de los árbitros. En este sentido, se podría incluir una referencia directa al Código de Ética de la CNUDMI o al de la International Bar Association (IBA). Con el mismo fin, se podría incorporar una referencia al artículo 1428 del Código de Comercio Mexicano. ${ }^{40}$ Las normas sobre ética de los árbitros ya figuran en los reglamentos de arbitraje; no obstante, al elevarlas al texto del TBI se lograría unificar los criterios aplicables en la materia y mostrar la importancia que esta cuestión reviste para recobrar parte de la legitimidad perdida del arbitraje internacional de inversiones.

controversia no podrá ser sometida a arbitraje de conformidad con lo establecido en esta Sección".

39 De ahí que se puede adoptar la siguiente redacción de un artículo, inspirándose del nuevo modelo de TBI de Países Bajos: "1. A menos que las partes contendientes acuerden otra cosa, el tribunal arbitral estará integrado por tres árbitros. Cada parte contendiente nombrará un árbitro, y las partes contendientes nombrarán de común acuerdo al tercer árbitro, quien será el presidente del tribunal arbitral. 2. Las partes pueden acordar que los miembros del tribunal arbitral sean nombrados por una Autoridad central: el Secretario General del CIADI para los procedimientos que se celebren bajo los auspicios de este Centro o el Secretario General de la CPI para los arbitrajes regidos por el Reglamento de Arbitraje de la CNUDMI".

40 En virtud de dicho artículo: "La persona a quien se comunique su posible nombramiento como árbitro deberá revelar todas las circunstancias que puedan dar lugar a dudas justificadas acerca de su imparcialidad o independencia. El árbitro desde el momento de su nombramiento y durante todas las actuaciones arbitrales, revelará sin demora tales circunstancias a las partes, a menos que ya se hubiera hecho de su conocimiento". 


\section{GONCLUSIÓN}

La actual regulación jurídica de los flujos de IED en el plano global no aporta respuestas eficaces a algunos "efectos perversos" de la liberalización y desregulación de dichas operaciones: entre otros, degradación del medio ambiente, "dumping jurídico", violaciones de derechos humanos e inexistente "responsabilidad social" de las empresas inversionistas. Ante la gravedad de dichos fenómenos, la reforma del régimen jurídico de los TBI se torna apremiante para todos los países, incluyendo México. La ausencia de una instancia multilateral que adopte modificaciones aplicables en el plano global, implica que la única vía para reformar dicho régimen sean las modificaciones unilaterales o selectivas de los modelos de TBI.

La gran desventaja de estas modificaciones se relaciona con el concepto de fórum shopping o la posibilidad que tienen los actores económicos de escoger entre los "foros" disponibles aquéllos que resulten más favorables para la defensa de su "causa". En el caso de una modificación selectiva de sólo algunos TBI, los inversionistas extranjeros podrían escoger instalarse en el territorio de los Estados que ofrezcan condiciones "más favorables" para el desarrollo de sus actividades económicas. Consecuentemente, la principal cautela de los Estados ante la adopción de nuevos modelos de TBI tiene que ver precisamente con la posibilidad de "asustar" a las IED y de provocar su "huida" hacia el territorio de otros países.

En este sentido, tal vez, la negativa actual de México de adoptar un nuevo modelo de TBI tenga que ver con la potencial pérdida de su carácter atractivo para las IED. No obstante, la decisión de un inversionista extranjero de instalarse en el territorio de un Estado no se basa únicamente en el contenido de sus TBI, sino que toma en cuenta factores más amplios, asociados con el denominado "riesgo país" (situación política, sistema bancario, imposición de restricciones comerciales, riesgos de expropiación, comportamiento de los consumidores, medidas fiscales, bloqueo de transferencia de fondos o no convertibilidad de divisas, burocracia gubernamental, corrupción, tasas de interés, tipos de cambio, nivel de inflación, crecimiento del PIB, tazas de desempleo, etcétera). Por ende, los efectos negativos de una modificación del marco jurídico internacional protector de las IED sobre la atracción de dichas operaciones no deben ser exagerados y sus consecuencias positivas serían, en todo caso, superiores. 


\section{REFERENCIAS}

Abengoa S. A. y Cofides S. A. vs. Estados Unidos Mexicanos. 2013. $\operatorname{ARB}(\mathrm{AF}) / 09 / 2$.

Acuerdo para la Promoción y Protección Recíproca de Inversiones entre los Estados Unidos Mexicanos y el Reino de España, EUM-ESP., 10 de octubre de 2006.

Archer Daniels Midland Company and Tate \& Lyle Ingredients Americas, Inc. vs. The United Mexican States. 2007. ARB (AF)/04/5.

Boeglin, Nicolas. 2013. "ICSID and Latin America: Criticisms, withdrawals and regional alternatives". Disponible en https://wrerw.bilaterals. org/?icsid-and-latin-america-criticisms Elang=en .

Cargill vs. México, 2009. ARB(AF)/05/2.

CNUCED. 2015, Transformation du régime des accords internationaux d'investissement, Note du Secretariat.

Conférence des Nations Unies Sur le Commerce et le Développement (CNUCED). 2012. Transparency: A Sequel, Collection de la CNUCED consacrée aux problèmes relatifs aux accords internationaux d'investissement II, ONU, Nueva York y Genève.

DUPRÉ, Mathilde. 2017. L'arbitrage d'investissement à la croisée des chemins, Alternatives Économiques. Disponible en http://wrwreveblen-institute.org/L-arbitrage-d-investissement-a-la-croisee-des-chemins.html.

EL Paso Energy International Company vs. The Argentine Republic. 2011. ARB/03/15.

FAYA RodRigues, Alejandro. 2013. “CCómo se determina una expropiación indirecta bajo tratados internacionales en materia de inversión? Un análisis contemporáneo": 219-246. Disponible en https://archivos.juridicas.unam.mx/www/bjo/libros/7/3386/8.pdf.

Gemplus S. A., SLP S. A., Gemplus Industrial S. A. de G.V. vs. The United Mexican States. 2010. ARB(AF)/04/3. ARB(AF)/04/4.

Hulley Enterprises Ltd. vs. Fédération de Russie, 2005. AA 226.

International Thunderbird Gaming Corporation vs. los Estados Unidos Mexicanos, Laudo arbitral TLCAN. 2006. párrafo 194.

Johnson, Lise y Volkov, Oleksandr. 2016. State Liability for Regulatory Change: How International Investment Rules are Overriding Domestic Law. https://wwweiisd.org/itn/2014/01/06/state-liability-for-regulatory-changehow-international-investment-rules-are-overriding-domestic-law/\#_ftn3.

Esta obra está bajo una Licencia Creative Commons

Atribución-NoComercial-SinDerivar 4.0 Internacional, IIJ-UNAM.

Boletín Mexicano de Derecho Comparado, núm. 158, mayo-agosto de 2020, pp. 863-894. 
Marvin Feldman vs. Estados Unidos Mexicanos. 2002. ARB (AF)/97/2

MENA, Paul. 2010, Ecuador pone fin a tratados bilaterales de inversiones. https:// wrerr.bbc.com/mundo/economia/2010/09/100915_ecuador_fin_tratados_bilaterales_inversiones_jp.

Metalclad Corporation vs. The United Mexican States. 1997. $\operatorname{ARB}(\mathrm{AF}) / 97 / 1$.

MONHEBURRun, Nitish. 2014. "Essay on unequal treaties and modernity through the example of bilateral investment treaties", Brazilian fournal of International Law, vol. 11.

MTD Equity Sdn. Bhd. \& MTD Chile S. A. c. República de Chile. 2004. $\mathrm{ARB} / 01 / 7$, párrafo 113.

Organización de Naciones Unidas (ONU). 2009. Contribution des accords internationaux d'investissement à l'attrait des pays en développement pour l'investissement étranger direct, Études de la GNUCED sur les politiques d'investissement international au service du développement, publication de l'ONU, New York.

Peacock, Nicholas, Surtani, Donny y Venugopal, Kritika. 2016. India seeks to re-negotiate Bilateral Investment Treaties with over 47 countries. Disponible en https://wrere.lexology.com/library/detail.aspx:g=e9408e6c-fa1b47cf-9206-8517de5ac5fc.

Ranjan, Prabhash, Vardhana, Harsha Singh, James, Kevin y Singh, Ramandeep. 2018. "India's Model Bilateral Investment Treaty: Is India Too Risk Averse?", Brookings India IMPACT. Series núm. 082018.

RIPINSKY, Sergey, "Venezuela's Withdrawal From ICSID: What it Does and Does Not Achieve". https://wrere.iisd.org/itn/fr/2012/04/13/vene zuelas-withdrawal-from-icsid-what-it-does-and-does-not-achieve/.

Robert Azinian, Kenneth Davitian y Ellen Baca vs. Estados Unidos Mexicanos. 1999. ARB(AF)/99/1, 16.

Saluka Investments BV vs. La República Checa. 2006, 255.

Sloss, David y VAn Alstine, Michael, 2015, "International Law in Domestic Courts". Faculty Scholarship at Santa Clara Law Digital Commons. http://digitalcommons.law.scu.edu/facpubs/889.

Sociedad General de Aguas de Barcelona S. A. and InterAgua Servicios Integrales del Agua S. A. vs. Argentine Republic 2018. ARB/03/17, párrafo 207.

SORnARAJAH, Muthucumaraswamy. 2000. The Settlement of Foreign Investment Disputes, The Hague Kluwer Law International: 408. 
Técnicas Medioambientales Tecmed, S. A. vs. United Mexican States 2003. $\operatorname{ARB}(\mathrm{AF}) / 00 / 2$, párrafo 154.

The Centre for Research on Multinational Corporations (SOMO), 2014, After South Africa, Indonesia takes a brave decision to terminate its Bilateral Investment Treaty with the Netherlands. https://wwre.somo.nl/after-south-africaindonesia-takes-a-brave-decision-to-terminate-its-bilateral-investment-treaty-withthe-netherlands/.

Total S. A. V. República Argentina. 2016. ARB/04/01, párrafo 122.

Transnational Institute (TNI). 2020. México profundiza derechos a los inversores extranjeros a pesar del alto número de demandas. Disponible en https://isdsamericalatina.org/mexico/\#notexi.

Transnational Institute (TNI), s. d., "Abengoa v México". Disponible en https://isds-americalatina.org/casos/abengoa-v-mexico/.

VAlero, Carmen. 2016. 'Juicio en Alemania al 'cerrojazo' nuclear de Merkel”. Disponible en http://wrere.elmundo.es/economia/2016/03/12/5 Ge326fb22601dae268b45a5.html.

VAlverde, Max. 2008. "Bolivia se margina del CIADI". Disponble en https://ictsd.iisd.org/bridges-news/puentes/news/bolivia-se-margina-del-ciadi.

VerbeeK, Bart-Jaap y KnOTTNERUs, Roeline. 2018. Le projet 2018 de TBI néerlandais: évaluation critique. Disponible en https://wwre.ïsd.org/itn/fr/ 2018/07/30/the-2018-draft-dutch-model-bit-a-critical-assessment-bart-jaapverbeek-and-roeline-knottnerus/.

Veteran Petroleum Ltd. vs. Fédération de Russie. 2005. AA 228.

Waste Management, Inc. vs. Estados Unidos Mexicanos. 2004. ARB(AF)/ $00 / 3$.

Yukos Universal Ltd. vs. Fédération de Russie. 2005. AA 227. 